\title{
Writing to families
}

\author{
Jean Gauthier
}

\section{Legislation and guidance}

The Data Protection Act 1984 gave patients access to health records held on computer. The Act sets out a series of principles to which all registered data users are expected to adhere notably, the requirement for personal data to be adequate, relevant and not excessive, accurate and up-to-date. An individual is entitled to have access to any such data at reasonable intervals and without undue delay or expense, and, where appropriate, to have such data corrected or erased. The exemptions to the 'right' of such access were also set out in the Act. The Royal College of Psychiatrists (1992) has already provided detailed guidance in relation to the Access to Health Records Act 1990. Given the increased use of word-processing facilities as a means of routine note-keeping, together with the implementation of computerised clinical audit systems recording detailed personal data on families, it is evident that these Acts will be viewed increasingly as complementary legislative frameworks. Where handwritten case notes continue to be the norm, the quality of notekeeping by professionals will need to be monitored continually within multi-disciplinary teams in view of the rising tide of medico-legal work, especially in child and adolescent psychiatry (Markantonakis \& Weir, 1991).

\section{The right to be informed}

From April 1988, in direct response to the implications of the Data Protection Act 1984, the author and all his subsequent trainees instituted the practice of routinely forwarding copies of all letters, follow-up summaries and reports to families. This change in clinical practice was instituted as a matter of the patient's and the family's right to see what was being written about him or her or them without their having to resort to the delaying procedures (and sometimes even the cost) of their gaining access to their own health records. The exemptions to the right of such access in terms of causing distress, or even harm, to the patient or to someone else, embodied in the Access to Health Records Act 1990, have always been borne in mind. Furthermore, the requirement that the disclosure of information, in relation to suspicions or the presence of abuse and/or where the child's best interests must always be paramount, has been kept constantly under careful consideration.

\section{Openness in practice}

Over the past 10 years, over 900 families have received letters and reports of their family meetings, as a routine part of their management. Thus, parents and their families can maintain their own complete duplicate record of their therapeutic progress from assessment to discharge. The normal practice is for the top copy to be sent to the referrer, with further copies sent to the network of involved professionals on a need to know' basis, agreed with the parents and their families in the first family assessment meeting. There are clearly major differences between communicating with teenagers (and their familles or not) and smaller children and their parents. As is evident in subsequent family meetings, all parents and most teenagers read what has been written about them - often with considerable interest. As would be expected, younger children are not expected to have read. nor to have taken particular interest in their reports. The situation in relation to individual psychotherapy/counselling with teenagers is, of course, rather different. Teenagers are always offered the option of receiving copies of their individual sessions but universally decline to do so, preferring instead the security, privacy and confidentiality of the clinic's file copy, which then can be read at the next session, if they so wish. In the case of play therapy with younger children. no copies of sessions are ever forwarded either to the parents or to the children themselves. This policy ensures that there are no potentially extremely damaging breaches in the confidentiality and the sensitivity of psychotherapeutic relationships.

At each encounter with the families, the text of the previous meeting is checked for factual inaccuracies, misleading phrases, misunderstood medical or technical terms, jargon and requests for the insertion of additional material, which may have been overlooked. Because it has been routine practice to incorporate not only the formulation but also the detailed management plan into these letters and follow-up reports, the 
text itself has come to be used as a working document, maintaining a link between the therapist and the family from session to session. In this way it has served as an 'aide-mémoire', not only in reminding the families themselves of the decisions that they reached in the previous meeting but also in maintaining an implied contractual commitment with the therapist to whom progress (or otherwise) is reported at each encounter.

\section{Setting appropriate boundaries}

Although families are entitled to have a written record of matters discussed within a meeting, therapists too need a certain degree of latitude to explore hypotheses and impressions in discussions with colleagues before and after family therapy meetings or psychotherapy sessions. A clear boundary needs to be drawn between the therapist's own private thoughts, creative ideas, impressions, feelings and hypotheses, which can be recorded in a separate section within the case notes and then tested in the next family therapy meeting or psychotherapy session.

\section{Jargon, value judgements and personal comments}

Within the Access to Health Records Act 1990. jargon is defined as "terms which are not intelligible without explanation". Furthermore, the Royal College of Psychiatrists' guidelines (1992) defined value judgements and personal comments as "statements about the patient based on the psychiatrist's subjective personal opinions". This would include offensive pejorative comments. College guidance on this issue makes it clear that there is no place for such language in modern case notes. Where medical and technical terms are used, they should be explained fully at the time of the meeting with the family, within the text or during the follow-up session. If a clinician is prepared to make a value judgement about an individual or about a family, then he or she should surely have the courage to make those comments face to face. Only then would it be justifiable for these value judgements to be recorded formally in subsequent reports.

\section{The spectre of litigation}

Before embarking on this policy in 1988, the possibility of exposing oneself to litigation through this openness in communication was considered very seriously, with advice sought from legal experts. One of the clinching arguments for adopting this practice in 1988 was that written records can be subpoenaed for civil or criminal proceedings in any event. Furthermore, it is routine practice for psychiatric reports to be made available to all parties in court proceedings under child care law when the content, conclusions and recommendations have such far reaching and often devastating implications for families. Clinicians are subjected to close crossexamination of all information in their court reports, their conclusions and their recommendations. Given that court reports have to be shared openly by all parties in such proceedings, how can we justify any residual reluctance or refusal on our part to do so in the management of routine cases?

\section{Comment}

When Butler \& Nicholls (1993) investigated the implications of the Access to Health Records Act 1990 on clinical practice among full-time qualified psychiatric staff, they found that the quality of psychiatric health records was improved, with more thought about what was written and less speculation in the notes.

More recently. Shah \& Pullen (1995) carried out a hospital audit on psychiatrists' letters to general practitioners. Their audit activity, prompted by the Access to Health Records Act 1990. resulted in less jargon and fewer value judgments in psychiatrists letters. The decision to adopt this openness of communication with families as a matter of policy has largely preempted and dispelled all the anticipated anxieties. In practice, the spectre of litigation simply has not materialised. There is no convincing evidence from the families themselves that this policy has had any deleterious psychological effects on family members, quite the reverse families have often been glowing in their praise of the quality of the reports. The knowledge that they are to be shared so openly provides an added motivation to ensure the highest possible standards of note-keeping and reporting in line with the best clinical practice. In so doing, it must surely meet any medico-legal requirements.

Finally, the National Health Service (NHS) Executive's Code of Practice on Openness in the NHS (NHS Executive, 1995), implemented in June 1995, fully endorses the principle that, in addition to any informal arrangements, patients have statutory rights of access to what has been written about them, subject to certain safeguards. The lid on the Pandora's Box of open communication has now been firmly prised open by legislation. It therefore remains for us, as clinicians, to enter open-mindedly into the spirit of this new enterprise. 


\section{Acknowledgements}

I am grateful to past and present colleagues with whom these issues have been closely debated, clarified and tested in daily clinical practice.

\section{References}

BUTLER, R. E. \& NiCHOLLS, D. E. (1993) The Access to Health Records Act: what difference does it make? Psychiatric Bulletin. 17, 204-206.

MARKANTONAKIS. A. \& WEIR. I. K. (1991) Medical audit quality note-keeping. Psychiatric Bulletin, 15, 283-284.
NHS EXEcuTtve (1995) Code of Practice on Openness in the NHS. London: NHS Executtve.

Royal College of PSYChIATRISTS (1992) Access to Health Records Act 1990. College guidance. Psychiatric Bulletin, 16, 114-116.

Sнан, P. J. \& PuLLen. I. (1995) The impact of a hospital audit on psychiatrists' letters to general practitioners. Psychiatric Bulletin. 19, 544-547.

Jean Gauthier, Consultant Child and Adolescent Psychiatrist and Clinical Director, Child Mental Health Services, The Wellcroft Centre, Wellcroft Road, Huyton, Merseyside L36 7TA

\section{Promoting Mental Health Internationally}

Editors: Giovanni Girolamo, Leon Eisenberg, David Goldberg, and John Cooper

To mark the retirement of Dr Norman Sartorius in 1974 from his post as Director of the Division of Mental health of the World Health

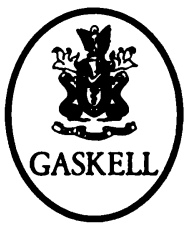
Organisation, the editors (all long-standing advisors and collaborators with the WHO programme) have brought together contributions from a mixture of advisors, collaborators and WHO staff members. The chapters provide descriptions and commentaries on the main aspects of the last 30 years of the WHO programme in mental health. The major topics and issues include the cross-cultural epidemiology and outcome of persons with serious mental illnesses, cross-cultural aspects of problems related to the misuse and control of alcohol and drugs of dependency, the role of psychiatry in primary care, and the development of a 'common language' for psychiatrists and mental health workers.

July 1999, Paperback, 192pp, ISBN 1901242 37 4, £25.00

Available from Book Sales, Royal College of Psychiatrists, 17 Belgrave Square, London SWIX 8PG Tel +44 (0) 1712352351 (extension 146) 9.30 am - 2 pm, Fax +44 (0) 1712451231 hHtp://uww.rcpsych.ac.uk 